\title{
BMJ Open Inequalities in excess premature mortality in England during the COVID-19 pandemic: a cross-sectional analysis of cumulative excess mortality by area deprivation and ethnicity
}

\author{
Sharmani Barnard (D) , ${ }^{1,2}$ Paul Fryers, ${ }^{1}$ Justine Fitzpatrick, ${ }^{1}$ Sebastian Fox, ${ }^{1}$ \\ Zachary Waller, ${ }^{1}$ Allan Baker, ${ }^{1}$ Paul Burton, ${ }^{1,3}$ John Newton, ${ }^{1}$ Yvonne Doyle, ${ }^{1}$ \\ Peter Goldblatt (iD) ${ }^{1,4}$
}

To cite: Barnard S, Fryers $P$, Fitzpatrick J, et al. Inequalities in excess premature mortality in England during the COVID-19 pandemic: a cross-sectional analysis of cumulative excess mortality by area deprivation and ethnicity. BMJ Open 2021;11:e052646. doi:10.1136/ bmjopen-2021-052646

- Prepublication history and additional supplemental material for this paper are available online. To view these files, please visit the journal online (http://dx.doi.org/10.1136/ bmjopen-2021-052646).

Received 21 April 2021 Accepted 08 0ctober 2021

Check for updates

(C) Author(s) (or their employer(s)) 2021. Re-use permitted under CC BY-NC. No commercial re-use. See rights and permissions. Published by BMJ.

For numbered affiliations see end of article.

Correspondence to

Paul Fryers;

paul.fryers@phe.gov.uk

\section{ABSTRACT}

Objectives To examine magnitude of the impact of the COVID-19 pandemic on inequalities in premature mortality in England by deprivation and ethnicity.

Design A statistical model to estimate increased mortality in population subgroups during the COVID-19 pandemic by comparing observed with expected mortality in each group based on trends over the previous 5 years.

Setting Information on deaths registered in England since 2015 was used, including age, sex, area of residence and cause of death. Ethnicity was obtained from Hospital Episode Statistics records linked to death data.

Participants Population study of England, including all 569824 deaths from all causes registered between 21 March 2020 and 26 February 2021.

Main outcome measures Excess mortality in each subgroup over and above the number expected based on trends in mortality in that group over the previous 5 years.

Results The gradient in excess mortality by area deprivation was greater in the under $75 \mathrm{~s}$ (the most deprived areas had 1.25 times as many deaths as expected, least deprived 1.14) than in all ages (most deprived had 1.24 times as many deaths as expected, least deprived 1.20). Among the black and Asian groups, all area deprivation quintiles had significantly larger excesses than white groups in the most deprived quintiles and there were no clear gradients across quintiles. Among the white group, only those in the most deprived quintile had more excess deaths than deaths directly involving COVID-19.

Conclusion The COVID-19 pandemic has widened inequalities in premature mortality by area deprivation. Among those under 75, the direct and indirect effects of the pandemic on deaths have disproportionately impacted ethnic minority groups irrespective of area deprivation, and the white group the most deprived areas. Statistics limited to deaths directly involving COVID-19 understate the pandemic's impact on inequalities by area deprivation and ethnic group at younger ages.

\section{STRENGTHS AND LIMITATIONS OF THIS STUDY}

$\Rightarrow$ This is the first study to identify important differences in excess premature mortality during the COVID-19 pandemic between ethnic groups in England.

$\Rightarrow$ We compare groups based on what would be expected, given the trends and demographic structures of the underlying populations in each group.

$\Rightarrow$ By comparing excess deaths, rather than COVID-19 deaths, we show both the direct and indirect impact of the pandemic on subgroups.

$\Rightarrow$ However, the ethnic groups used in the analysis are broad and may hide important differences among ethnic subgroups.

$\Rightarrow$ Accounting for area deprivation using quintiles of small areas does not necessarily identify deprived individuals or households within areas, so the association between individual deprivation and excess deaths may differ from that identified in this study.

\section{INTRODUCTION}

Inequalities in mortality from COVID-19 have been widely reported by age, gender, area deprivation and ethnic group. ${ }^{1-5}$ Mortality from COVID-19 has been highest among older groups, with people aged over 80 years estimated to have 70 times the risk of mortality from COVID-19 once infected, compared with those aged under 40 years. ${ }^{3}$ Mortality from COVID-19 among males has been higher than in females and, after controlling for age and comorbidities, mortality from COVID-19 among many ethnic minority groups has been higher than the white group. ${ }^{367}$

There is consistent evidence that mortality rates for deaths associated with COVID-19 during the first wave of the pandemic were more than twice as high among people living in the most deprived areas compared with those living in the least deprived areas. ${ }^{3} 58$ 
However, all-cause mortality was also higher among the most deprived areas in previous years. ${ }^{39}$

Measures of excess mortality compare the mortality that would be expected in each group, based on trends in previous years, with what has occurred in that group. ${ }^{41011}$ They, therefore, take account of the existing inequalities in the baseline and show the extent to which COVID-19 has impacted on inequalities between groups. Estimates of excess mortality for all ages combined for the period March 2020 to February 2021 show a small difference in the relative impact of COVID-19 on excess mortality between the most deprived and the least deprived, and show a greater excess in ethnic minority groups. ${ }^{12}$ However, these estimates have not been presented separately for each ethnic group by deprivation. In addition, these overall estimates are heavily weighted towards deaths at older ages because of the far higher death rates in older people.

Understanding the relationship between area deprivation, ethnicity and excess mortality among the those aged under 75 years is important for four reasons. First, there is an existing gradient in mortality among deprivation groups; in the years prior to the COVID-19 pandemic a third of premature deaths ( $<75$ years) were attributable to socioeconomic inequality. ${ }^{13}$ Second, when comparing the mortality that has occurred during the pandemic with what would have been expected in the absence of the pandemic, the relative increase has been highest among those aged 45 to 64 years. ${ }^{12}$ Third, we know that COVID-19 death rates have been higher in ethnic minority groups and deprived areas, but we do not fully understand the interaction between the two. ${ }^{3}$ Fourth, the deprivation quintile allocated to care homes based on their address, where a significant proportion of people over 75 reside, may not accurately reflect the lifetime deprivation of the care home residents and may play a role in masking the relationship between excess mortality and area deprivation at older ages.

In this study, we investigate the relationship between age, area deprivation, ethnicity and mortality, by estimating excess mortality for each area deprivation quintile among those aged under 75 (premature mortality) for each ethnic group. By doing this, we aim to identify the magnitude of the increase in overall mortality that occurred during the COVID-19 pandemic in each ethnic group in each area deprivation quintile, based on what would have been expected for these groups. This will, therefore, identify any increases in inequalities that are over and above existing inequalities in mortality between area deprivation quintiles in each ethnic group.

\section{METHODS}

\section{Setting}

The first reported death due to COVID-19 in England was on 5 March 2020. ${ }^{14}$ Public Health England (PHE) began receiving a daily feed of registered deaths from the Office for National Statistics (ONS) on 21 March 2020 to enable timely analysis of mortality during the pandemic. We examined excess mortality in England by area deprivation quintile from 21 March 2020 to 26 February 2021. All registered deaths of usual residents of England in this period ( $\mathrm{N}=569824)$ were included in the analysis. All those deaths recorded as mentioning COVID-19 on the death certificate (directly involving COVID-19) in England until 26 February 2021 were thus incorporated in the analysis, except for 76 COVID-19 deaths registered before 21 March 2020. All analyses were carried out on 10 March 2021.

\section{Measuring excess mortality}

Analyses

All analyses included deaths from all causes. We investigated excess mortality by deprivation quintile separately among all persons of all ages and among those aged under 75 years. We also present excess mortality estimates for each deprivation quintile by ethnic group among those aged under 75 .

\section{Data and methods}

The data and methods used by PHE to estimate excess mortality for weekly national excess reports were adopted for this analysis. ${ }^{12}$ The number of excess deaths in each group is the number of observed deaths relative to the number of deaths that would have been expected based on trends in data from the previous 5 years for that group (baseline deaths).

To estimate rates of expected deaths in 2020 and 2021, Quasi-Poisson regression models were fitted on the logarithmic scale using a combination of deaths and population denominator data from 2015 to 2019 . These rates were then applied to population projections for 2020 and 2021. Independent variables included whether the week contained a public holiday, and time of year, allowing for seasonal effects. Adjustments were made for registration fluctuations around public holidays. Covariates included age, gender, area deprivation, ethnicity and geographical area. A linear trend was also included in the model to take in to account any systematic changes in the rate of death that are not reflected in the changing age structure of the population.

Area deprivation was measured by the 2019 Index of Multiple Deprivation ${ }^{15}$ for the Lower Super Output Area (LSOA) of postcode of residence. LSOAs were allocated to national quintiles based on the deprivation score. Data for deprivation were complete for all records. Ethnicity was measured at the individual level through linkage to Hospital Episode Statistics (HES). For deaths this linkage resulted in $98 \%$ to $99 \%$ of records being linked (varying year on year) and $2.7 \%$ of records having a 'not stated' or 'not known' ethnicity. Among those not linked, not stated or not known, ethnic group was assigned proportionally based on 2011 ONS Census populations, stratified for age, sex and region.

Prediction intervals (PIs) were calculated to account for both the uncertainty in the underlying model and the anticipated stochastic variation in the observed number of deaths, to give a range of plausible observed values 
consistent with the modelled expected values. The width of PIS was estimated by generating random samples from a Quasi-Poisson distribution with the appropriate modelled rates of death and the estimated dispersion parameter. Upper and lower PIs were then obtained by estimating the 0.001 and 0.999 quantiles (ie $\pm 3 \mathrm{SD}$ ) of this distribution.

Further details of the data sources and statistical modelling are available in the methodology documentation included with the weekly reports. ${ }^{11}$ All data were analysed using the generalised linear modelling function in the statistical package R (V.4.0.3). ${ }^{16}$

\section{Patient and public involvement}

It was not appropriate or possible to involve patients or the public in the design, or conduct, or reporting, or dissemination plans of the research.

\section{RESULTS \\ Excess mortality by area deprivation quintile among all persons}

Between 21 March 2020 and 26 February 2021, we estimate there were 101501 excess deaths among all persons in England. This is 1.22 times the number of deaths expected, had there been no pandemic. There was a slight gradient in the relative excess mortality of the most deprived area quintile (1.24 times the expected; $99.8 \%$ PI 1.24 to 1.25 ) to the least deprived (1.20 times; $99.8 \%$ PI 1.19 to 1.21 ) (online supplemental figure 1). In every area deprivation quintile, the number of deaths with COVID-19 mentioned on the death certificate (124437 in all) exceeded the number of excess deaths (online supplemental table 1).

\section{Excess mortality by area deprivation quintile among persons aged $<75$}

Among those aged under 75 years, 177809 deaths were registered in the same period-29845 more than expected or 1.20 times (99.8\% PI 1.19 to 1.21$)$ the number expected based on trends in previous years (table 1). There was a steeper gradient in excess mortality by area deprivation quintile compared with the analysis of all ages, with excess mortality highest in the most deprived areas (1.25 times the expected; $99.8 \%$ PI 1.24 to 1.27 ) and lowest among the least deprived

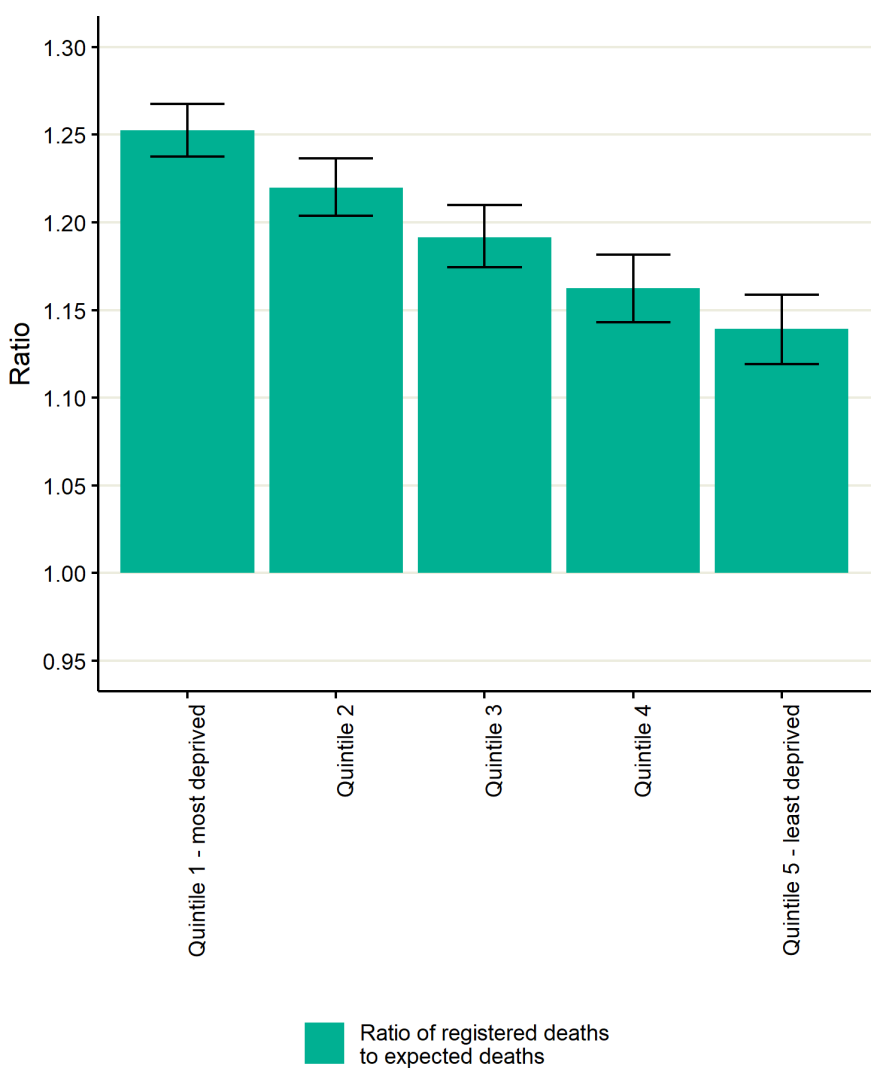

Figure 1 Excess mortality by area deprivation quintile among people aged less than 75 years, 21 March 2020 to 26 February 2021.

(1.14 times; $99.8 \%$ PI 1.12 to 1.16 ) (figure 1 ). This difference in gradient largely results from lower excess mortality in the three least deprived area quintiles among those under 75 years, compared with all age groups. In the most deprived area quintile, there were more excess deaths than deaths with COVID-19 on the death certificate (table 1).

\section{Area deprivation by ethnic group among the $<75$ s}

Excess mortality among those aged under 75 years by ethnic group and area deprivation quintile is presented in figure 2 and table 2. Among those under 75, the White population saw the smallest relative excess compared with the number expected (1.17; $99.8 \%$ PI 1.16 to 1.17$)$. The Asian (1.63; $99.8 \%$ PI 1.60 to 1.67$)$ and black $(1.58 ; 99.8 \%$ PI 1.53 to

Table 1 Excess mortality by area deprivation quintile among people aged <75 years, 21 March 2020 to 26 February 2021

\begin{tabular}{|c|c|c|c|c|c|}
\hline Area deprivation quintile & Expected deaths* & $\begin{array}{l}\text { Registered } \\
\text { deaths }\end{array}$ & $\begin{array}{l}\text { Ratio registered/ } \\
\text { expected }^{*}\end{array}$ & Excess deaths* & $\begin{array}{l}\text { COVID-19 } \\
\text { deaths }\end{array}$ \\
\hline Quintile 1-most deprived & $40161(39566,40783)$ & 50306 & $1.25(1.24,1.27)$ & $10145(9523,10740)$ & 9887 \\
\hline Quintile 3 & $28527(28026,29016)$ & 33989 & $1.19(1.17,1.21)$ & $5462(4973,5963)$ & 6088 \\
\hline Quintile 4 & $25384(24889,25854)$ & 29504 & $1.16(1.14,1.18)$ & $4120(3650,4615)$ & 4975 \\
\hline
\end{tabular}

${ }^{\star}$ Excess deaths are derived from the difference between the observed registered deaths and the modelled estimate of expected registered deaths. Intervals represent $99.8 \%$ prediction intervals. 


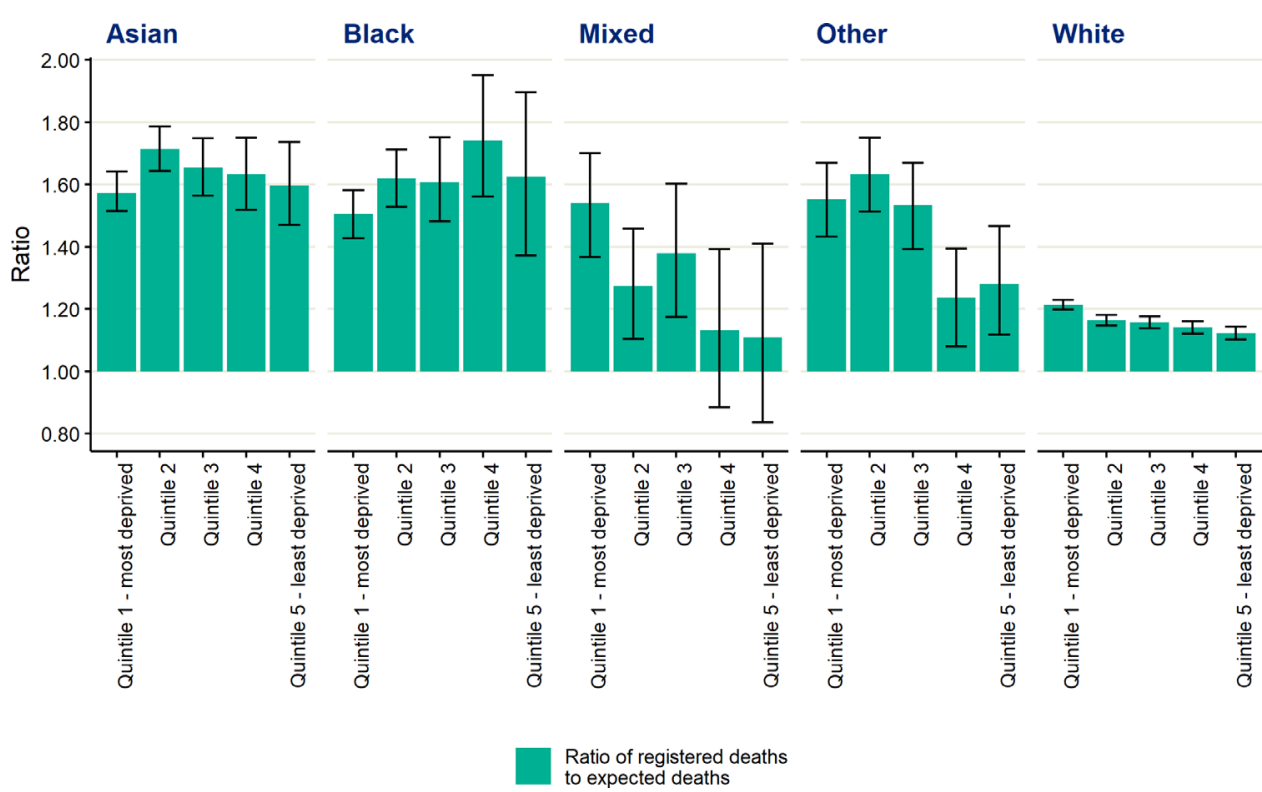

1.63) populations saw the largest relative increase in deaths compared with the number of deaths expected based on previous years.

Among the white group, there was a clear gradient of relative excess between the most deprived areas (1.21; 99.8\% PI 1.20 to 1.23$)$ and the least deprived (1.12; $99.8 \%$ PI 1.10 to 1.14). Among the Asian population, those in all deprivation groups experienced a relative excess between $1.57(99.8 \%$ PI 1.52 to 1.63$)$ and 1.71 times (99.8\% PI 1.64 to 1.78$)$ but there was no obvious gradient with area deprivation, and no significant differences between the quintiles. In the black population, those in all deprivation groups had between 1.51 (99.8\% PI 1.43 to 1.58 ) and 1.74 times (99.8\% PI 1.56 to 1.93 ) the expected number of deaths, again with no clear gradient and no significant differences between the quintiles. However, among the black and Asian groups, those in all deprivation quintiles saw far greater excesses; significantly greater than even the white group in the most deprived areas. In the mixed and other groups, there is the suggestion of a gradient, with a higher excess among those in the more deprived groups, but with very large CIs.

Among the white group, the number of deaths directly involving COVID-19 was higher than the number of excess deaths in for all deprivation quintiles except the most deprived. This was not seen among the other ethnic groups (table 2). Full details of excess mortality by area deprivation for ethnic groups are presented in table 2.

\section{DISCUSSION}

\section{Principal findings}

Among those aged under 75 years, excess mortality (compared with expected deaths based on that group's mortality trends in 2015 to 2019) was clearly associated with area deprivation: highest in the most deprived and lowest among the least deprived areas. Since higher mortality rates among the more deprived areas prior to the pandemic are taken into account in modelling the expected deaths, this gradient across the deprivation spectrum indicates a stark increase in already established inequalities in premature mortality.

Excess mortality was also clearly associated with ethnicity, with higher overall excess in the black, Asian, mixed and other ethnic groups than the white group. However, the relationship between excess mortality and deprivation is not consistent across ethnic groups: while the white group saw a clear positive gradient between excess mortality and increased area deprivation, among black and Asian groups there was no clear gradient and all deprivation quintiles saw far greater excess than even the white group in the most deprived area quintile. This indicates that ethnicity is a determinant of excess mortality, regardless of level of area-based deprivation.

The extent to which excess deaths can be explained by those directly involving COVID-19 is not consistent between ethnic groups and across area deprivation quintiles. In the white group, all of the deprivation quintiles except for the most deprived group experienced fewer excess deaths compared with COVID-19 deaths. This was not the case for other ethnic groups, including the black group for whom, among the all age population, there were significantly fewer COVID-19 deaths than excess deaths. These differences in excess deaths not attributable to COVID-19 between the white in the most deprived area quintile and more generally among ethnic minority groups may indicate a lack of recording of COVID-19 on death certificates when testing was limited at the start of the pandemic, or deaths indirectly caused by the pandemic. This may be through factors such as more limited access to healthcare for conditions other than COVID-19, the impact of measures taken to combat 
Table 2 Excess mortality by area deprivation quintile and ethnic group among people aged $<75$ years, 21 March 2020 to 26 February 2021

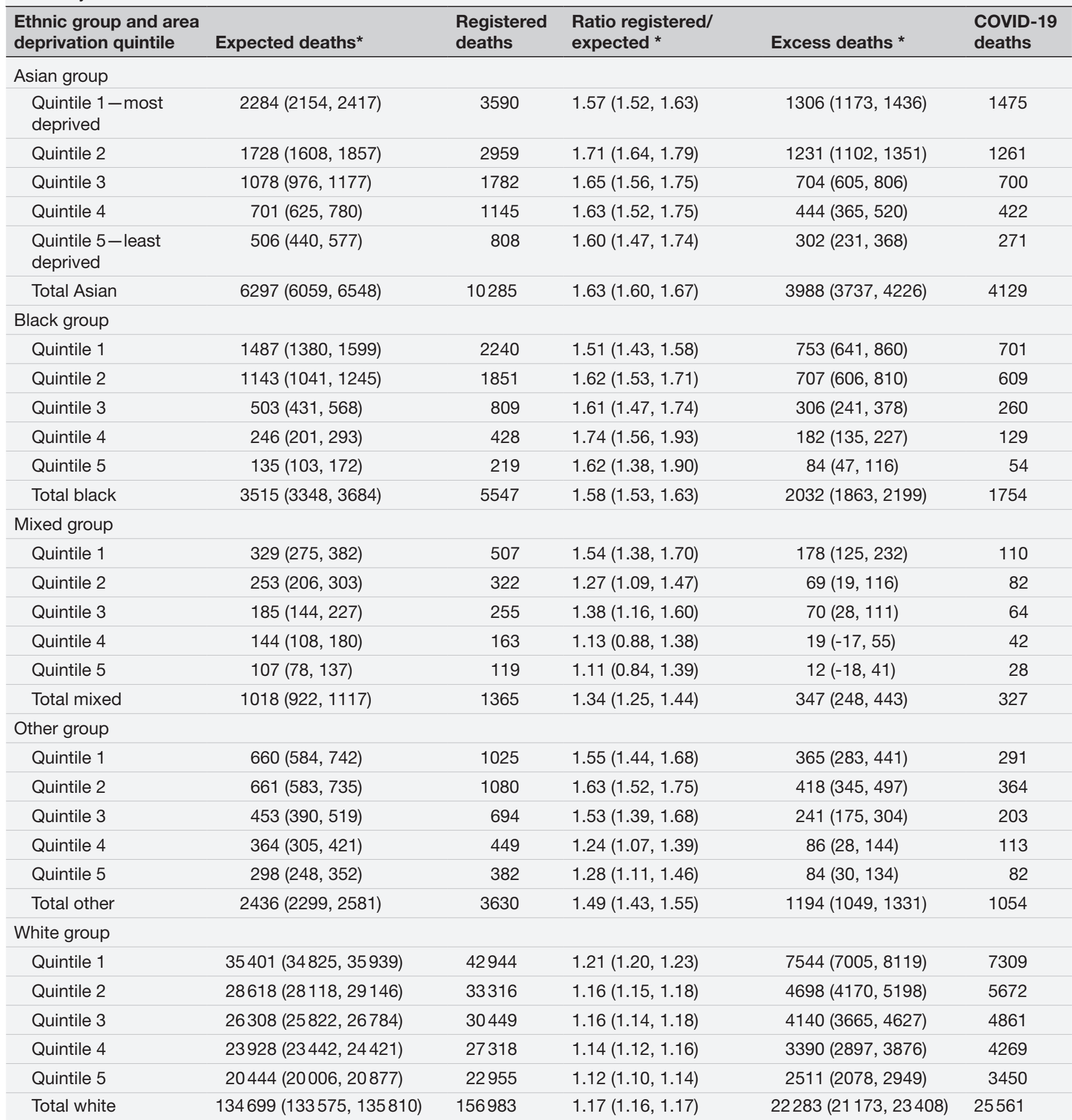

${ }^{*}$ Excess deaths are derived from the difference between the observed registered deaths and the modelled estimate of expected registered deaths. Intervals represent $99.8 \%$ prediction intervals.

the spread of the virus or other consequences of the pandemic. This warrants further analysis and investigation; it is possible that the impact could be reduced by ensuring access to the National Health Service (NHS), take up of COVID-19 testing, and addressing the wider impact of lockdown, such as mental health and financial issues. Understanding how these factors affect ethnic groups differentially is critical to reducing inequalities.

\section{Possible mechanisms and implications of the results}

The prevalence of many long-term health conditions is greater in some ethnic minority populations and 
deprived communities which may also be a factor. ${ }^{17-19}$ One survey, based on data up to the end of January 2021, found $51.9 \%$ of the of the population did not seek help for a worsening health condition during the pandemic. ${ }^{20}$ Long-term conditions have very different treatment pathways and the wider impact of the pandemic may not be the same for all. For example, hypertensive symptoms or increasing angina are signals for attendance at Accident and Emergency (A\&E) Departments, but a growing or deteriorating cancer would have been affected by the cancellation of elective clinics, referrals from primary care, or postponement of screening services. These differential impacts of this may not yet be fully realised or understood.

This study shows a greater widening of inequality in premature mortality than deaths at all ages. However, the impact of the pandemic on people in care homes has been substantial and $24 \%$ of all deaths involving COVID-19 between 21 March 2020 and 26 February 2021 occurred in care homes. ${ }^{12}$ The large number of people aged over 75 years in care home facilities, where the deprivation quintile in which the care home is located may not accurately reflect the lifetime deprivation of the care home residents, may play a role in altering the relationship between excess mortality and deprivation at older ages. In addition, the Vivaldi study has shown that there are many other factors that have influenced the impact of the pandemic on individual care homes such as location, characteristics of the home and staffing arrangements which may mean this relationship is not straightforward. ${ }^{21}$

Our study shows that, like major historical pandemics in Europe, the COVID-19 pandemic has disproportionately impacted the most deprived. ${ }^{22-24}$ Effects of this sort are not limited to pandemics; the slowdown in improvement in life expectancy in England in the decade before the pandemic also disproportionately affected populations in the most deprived areas and inequalities widened, but the pace of change was slow in comparison to that seen over the period examined in this study. ${ }^{25}$

\section{Strengths and limitations}

This study has many strengths. It is the first study to investigate the relationships between area deprivation and excess mortality during the pandemic among those aged less than 75 and among ethnic groups in England, and to identify important differences across subgroups. The method we employed provides a useful tool to identify inequalities in excess mortality among different groups because baseline deaths are constructed on what would be expected, given the trends and demographic structures of the underlying populations in each group. It estimates the magnitude of the increase in overall mortality during the COVID-19 pandemic, including both deaths involving COVID-19 and deaths caused by the wider impact of the pandemic.

However, this study does have some limitations. The ethnic groups used in the analysis are broad and may hide important differences among ethnic subgroups.
This is particularly important for the Asian group, among whom there is evidence of variation in COVID-19 outcomes between Bangladeshi, Pakistani and Indian groups. ${ }^{36}$ Broad ethnic groups were analysed instead of more detailed groups to reduce bias caused by differences in the recording of ethnicity between the denominator data for populations (Census data) and information obtained on deaths using hospital activity data (HES data). Ethnicity in hospital records is often collected by healthcare staff who may be more likely to record ethnicity as 'other' ethnic groups, (such as 'Black Other' and 'Asian other'), or to misclassify ethnicity if they are not sure of the ethnicity of the patient. This may have occurred more often during the COVID-19 outbreak, when fewer family members were present in hospitals. Therefore, there may be a greater number of excess deaths among 'black other' and 'Asian other' ethnic groups and more misclassification of ethnicity during the COVID-19 outbreak that would not be reflected in the denominators. Therefore, the number of excess deaths among 'other' ethnic groups should also be interpreted with some caution due to this potential mismatch.

Accounting for deprivation using quintiles of small areas does not imply that all individuals or households within areas have the same level of deprivation, so the association between individual deprivation and excess deaths may differ from that identified in this study. We were unable to exclude care home residents from the analysis because there was no reliable way of excluding the corresponding population from the denominators. Some care home residents will remain in this analysis, though by restricting people aged under 75 this group is likely to be small. This analysis describes differences in excess mortality between groups, though it does not look for factors that may be driving these differences; those that increase risk of infection such as household size or occupation; and those that increase risk of death following infection, such as late presentation at hospital. ${ }^{36}$ Finally, the relative impact of the pandemic on sub-groups of the population may have varied throughout the pandemic period and by geography; by presenting the cumulative estimates we are not able to identify this variation.

\section{Unanswered questions and future research}

Our findings need further investigation as to why these differences in mortality between ethnic groups independent of deprivation exist; a first step could be to look at underlying morbidities and aspects of deprivation not measured in the index used. Further work is also required to understand how the relationship between deprivation, ethnicity and excess mortality may have changed over the course of the COVID-19 pandemic and will change into the future. It is also important to examine where the deaths occurred as we know that during the pandemic to date there have been many excess deaths from causes other than COVID-19 that have occurred at home while there have been more COVID-19 deaths in hospital than excess deaths in hospital. ${ }^{12}$ What is not known is whether 
this was people choosing to die at home instead of hospital or people avoiding hospitals and experiencing an earlier death as a result. The relationship between excess deaths not directly attributable to COVID-19 and the period the death occurred during the pandemic (eg, wave one or wave two) should also be explored. It is not clear the extent to which these are influenced by measures to control the spread of the virus (ie, lockdowns may have prevented spread of other respiratory pathogens), mortality displacement or longer-term implications of COVID-19 infection. However, the lack of availability of diagnostic testing early in the pandemic may have resulted in misclassification COVID-19 deaths as deaths due to other causes which may limit further investigation of this using routinely collected population data.

We illustrate the importance of examining the relationship between area deprivation and excess deaths among defined age groups and ethnic groups. To date, routine surveillance of excess deaths during the COVID-19 pandemic both by ONS and PHE has not revealed this relationship; both organisations have reported results separately by age, area deprivation and ethnic group. ${ }^{126}$ Surveillance that reveals these inequalities will become increasingly important as the medium and long-term implications of the pandemic are revealed. ${ }^{24}$

Even though analysis of death certificate information does highlight inequalities in mortality involving COVID-19, analysis of all-cause excess deaths shows that the impact on inequalities is even greater: the indirect effect of the pandemic on deaths has disproportionately affected people in ethnic minority groups and the White group in the most deprived areas. The COVID-19 pandemic has already increased inequalities in premature mortality between social and ethnic groups beyond those that existed in 2015-2019, and we do not yet understand the long-term implications, including the impact of 'long COVID-19' on mortality.

\section{Author affiliations}

${ }^{1}$ Health Intelligence, Public Health England, London, UK

${ }^{2}$ ARC Centre of Excellence for Children and Families over the Life Course (Life Course Centre), Telethon Kids Institute, Nedlands, Western Australia, Australia ${ }^{3}$ Population Health Sciences Institute, Newcastle University, Newcastle upon Tyne, UK

${ }^{4}$ UCL Institute of Health Equity, University College London, London, UK

Contributors SB is the guarantor of the study and accepts full responsibility for the work, had access to the data and controlled the decision to publish. All authors contributed to the study design, overall analysis plan and critically reviewed the final manuscript. Specifically, PG, JF, PF, SB, SF and AB conceived the study; SB and PF drafted the manuscript; JF, YD, JN, PB, AB and PG critically reviewed the analysis plan and revised the paper; and SF and ZW obtained the data, carried out the analysis and produced the graphs. All authors critically reviewed the final paper.

Funding SB acknowledges funding received from the ARC Centre of Excellence for Children and Families over the Life Course (Life Course Centre).

Competing interests None declared.

Patient consent for publication Not applicable.

Ethics approval This study was carried out as part of the PHE responsibility to manage the COVID-19 pandemic. PHE has legal permission, provided by Regulation 3 of The Health Service (Control of Patient Information) Regulations 2002 to process confidential patient information (http://www.legislation.gov.uk/uksi/2002/1438/ regulation/3/made) under Sections 3(i) (a) to (c), 3(i)(d) (i) and (ii) and 3(3) as part of its outbreak response activities. As such this work falls outside the remit for ethical review. The weekly surveillance process makes use of identifiable data. However, this study was based on anonymised aggregated outputs from that process. The study was subject to an internal review by the PHE Research Ethics and Governance Group and was found to be fully compliant with all regulatory requirements. As a full ethical review is not a requirement for this type of study and as no ethical or regulatory issues had been identified the study was approved.

Provenance and peer review Not commissioned; externally peer reviewed.

Data availability statement Data are available on reasonable request. Data availability statement: Data are available upon reasonable request. All data relevant to the study are included in the article or uploaded as supplemental information.

Supplemental material This content has been supplied by the author(s). It has not been vetted by BMJ Publishing Group Limited (BMJ) and may not have been peer-reviewed. Any opinions or recommendations discussed are solely those of the author(s) and are not endorsed by BMJ. BMJ disclaims all liability and responsibility arising from any reliance placed on the content. Where the content includes any translated material, BMJ does not warrant the accuracy and reliability of the translations (including but not limited to local regulations, clinical guidelines, terminology, drug names and drug dosages), and is not responsible for any error and/or omissions arising from translation and adaptation or otherwise.

Open access This is an open access article distributed in accordance with the Creative Commons Attribution Non Commercial (CC BY-NC 4.0) license, which permits others to distribute, remix, adapt, build upon this work non-commercially, and license their derivative works on different terms, provided the original work is properly cited, appropriate credit is given, any changes made indicated, and the use is non-commercial. See: http://creativecommons.org/licenses/by-nc/4.0/.

\section{ORCID iDs}

Sharmani Barnard http://orcid.org/0000-0001-7582-5558

Peter Goldblatt http://orcid.org/0000-0003-0491-2077

\section{REFERENCES}

1 Office for National Statistics. Analysis of death registrations not involving coronavirus (COVID-19), England and Wales: 28 December 2019 to 1 may 2020. Office for National Statistics, 2020.

2 Office for National Statistics. Coronavirus (COVID-19) related deaths by ethnic group, England and Wales: 2 March 2020 to 10 April 2020. United Kingdom Office for National Statistics, 2020.

3 Public Health England. Disparities in the risk and outcomes from COVID-19, 2020. Available: https://www.gov.uk/government/ publications/covid-19-review-of-disparities-in-risks-and-outcomes

4 Sinnathamby MA, Whitaker $\mathrm{H}$, Coughlan L, et al. All-Cause excess mortality observed by age group and regions in the first wave of the COVID-19 pandemic in England. Euro Surveill 2020;25:2001239.

5 Office for National Statistics. Deaths involving COVID-19 by local area and socioeconomic deprivation: deaths occurring between 1 March and 31 July 2020, 2020.

6 Public Health England. Analysis of the relationship between preexisting health conditions, ethnicity and COVID-19 diagnosis and death, 2020. Available: https://assets.publishing.service.gov.uk/ government/uploads/system/uploads/attachment_data/file/942091/ Summary_report_ethnicity_and_comorbidity.pdf

7 Office for National Statistics. Updating ethnic contrasts in deaths involving the coronavirus (COVID-19), England and Wales: deaths occurring 2 March to 28 July 2020, 2020. Available: https://www.ons. gov.uk/peoplepopulationandcommunity/birthsdeathsandmarriages/ deaths/articles/updatingethniccontrastsindeathsinvolvingthecoron aviruscovid19englandandwales/deathsoccurring2marchto28july2020

8 lacobucci G. Covid-19: deprived areas have the highest death rates in England and Wales. BMJ 2020;369:m1810.

9 Office for National Statistics. Changing trends in mortality by National indices of deprivation, England and Wales: 2001 to 2018. Office for National Statistics, 2020.

10 Vestergaard LS, Nielsen J, Richter L, et al. Excess all-cause mortality during the COVID-19 pandemic in Europe - preliminary pooled estimates from the EuroMOMO network, March to April 2020. Euro Surveill 2020;25:2001214.

11 Public Health England. Excess mortality in England: methodology for the Weekly reports. London: Public Health England, 2020.

12 Public Health England. Excess mortality in England, week ending 26 February 2021, 2021. Available: https://fingertips.phe.org.uk/static- 
reports/mortality-surveillance/excess-mortality-in-england-weekending-26-Feb-2021.html

13 Lewer D, Jayatunga W, Aldridge RW, et al. Premature mortality attributable to socioeconomic inequality in England between 2003 and 2018: an observational study. Lancet Public Health 2020;5:e33-41.

14 BBC News. Coronavirus: woman in 70S becomes first virus fatality in UK. BBC News, 2020. https://www.bbc.com/news/uk-51759602

15 Ministry of Housing Communities and Local Government. English indices of deprivation 2019, 2019. Available: https://www.gov.uk/ government/statistics/english-indices-of-deprivation-2019

16 R Core Team. A language and environment for statistical computing. $R$ foundation for statistical computing, 2020.

17 Watkinson RE, Sutton M, Turner AJ. Ethnic inequalities in healthrelated quality of life among older adults in England: secondary analysis of a national cross-sectional survey. Lancet Public Health 2021;6:e145-54.

18 NHS Digital. Health survey for England 2018: longstanding conditions, 2019.

19 Raleigh V, Holmes J. The health of people from ethnic minority groups in England. The King's Fund, 2021.
20 Public Health England. Wider impacts of COVID-19 on health (wich) monitoring tool, 2021.

21 Office for National Statistics. Impact of coronavirus in care homes in England, 2020. Available: https://www.ons.gov.uk/peoplepo pulationandcommunity/healthandsocialcare/conditionsanddis eases/articles/impactofcoronavirusincarehomesinenglandvivaldi/ 26mayto19june2020\#covid-19-surveillance-study-in-care-homesvivaldi

22 Ahmed F, Ahmed Na'eem, Pissarides C, et al. Why inequality could spread COVID-19. Lancet Public Health 2020;5:e240.

23 Bambra C, Norman P, Johnson NPAS. Visualising regional inequalities in the 1918 Spanish flu pandemic in England and Wales. Environment and Planning A: Economy and Space 2021;53:607-11.

24 Bambra C, Riordan R, Ford J, et al. The COVID-19 pandemic and health inequalities. J Epidemiol Community Health 2020;74:964-8.

25 Public Health England. A review of recent trends in mortality in England, 2018. Available: https://assets.publishing.service.gov.uk/ government/uploads/system/uploads/attachment_data/file/827518/ Recent_trends_in_mortality_in_England.pdf

26 Office for National Statistics. Deaths registered Weekly in England and Wales, provisional: week ending, 2021. 